\title{
Mendidik Warga Negara Indonesia Di Sekolah Dasar: Perspektif Guru
}

\author{
Fauzi Abdillah \\ Universitas Pendidikan Indonesia \\ abdillah@upi.edu
}

\begin{abstract}
Abstrak
Penelitian ini berangkat dari kebutuhan data kontekstual mengenai sejauh mana pelaksanaan pembelajaran PPKn, perspektif guru pada materi PPKn dan prospek pengembangan materi PPKn pada tingkat sekolah dasar berdasarkan revisi kurikulum 2013 pada tahun 2016. Data tersebut dibutuhkan dalam rangka pengembangan konten materi perkuliahan di tingkat pendidikan sarjana, khususnya bagi program studi PGSD. Penelitian ini dilaksanakan dengan pendekatan kualitatif melalui metodologi penelitian Grounded theory, penelitian ini menelusuri, memetakan dan menganalisis data terkait materi PPKn SD, khususnya persepsi dan implementasi pembelajaran guru yang mengacu pada materi PPKn di tingkat Sekolah Dasar. Hasil penelitian memberi gambaran mengenai perspektif guru terhadap konten materi PPKn di Kurikulum Nasional revisi 2016, ini sebagai media dan strategi paling relevan untuk meningkatkan kesadaran siswa terhadap nilai, moral, kecakapan hidup bermasyarakat nantinya. Sehingga, rekomendasi untuk konten materi perkuliahan ke-PKn-an di PGSD juga harus berorientasi pada pemenuhan akan pendalaman pada ketiga hal tersebut.
\end{abstract}

Kata Kunci: Perspektif Guru SD, PPKn SD, Kurikulum nasional

\begin{abstract}
This research is based on contextual data on the extent to which the implementation of civic education, the teacher's perspective on Pancasila and Civic Education (PPKn) materials and the prospects for its material development at the primary school level based on the revision of the 2013 curriculum in 2016. Data is required in the development of lecture content materials at the undergraduate level of PGSD. This research is done by qualitative approach through grounded theory research methodology, this research is tracing, mapping and analyzing data related to PPKn in Elementary School, especially on perspective and teacher implementation to civic education materials at elementary school level. The results provide an overview of the teacher's perspective on the content of PPKn materials in the revised 2016 National Curriculum, which views these subjects as the most relevant medium for raising students' awareness of community values, morals, and life skills in the future. Recommendations for lecture content materials related to Civic Education in PGSD will also be oriented to the fulfilment on the depth to the three items mentioned above.
\end{abstract}

Keywords: Elementary School Teacher Perspectives, Civic Education in elementary School, National Curriculum

\section{PENDAHULUAN}

Pendidikan dasar menjadi masa kritis untuk membiasakan civic habits sebagai persiapan untuk berkontribusi dalam kehidupan nyata. (Parker, 2011) Tantangan zaman yang dinarasikan sebagai dorongan untuk perubahan kurikulum pendidikan di Indonesia melahirkan beragam perubahan kebijakan. Pada tahun 2016, terjadi revisi pada Kurikulum Nasional yang biasa disebut sebagai kurikulum 2013. Di sana terjadi beberapa perubahan dalam hal fundamental, operasional dan konten material. Dengan membatasi studi ini pada konteks sekolah dasar, khususnya pada area Pendidikan Pancasila dan Kewarganegaraan, studi ini menyelidiki apakah perubahan tersebut sudah sesuai dengan landasan PPKn, kebutuhan lapangan, kompetensi guru dan strategis dalam menghadirkan warga negara yang tak hanya cerdas tapi juga baik. Para sarjana bidang Pendidikan Kewarganegaraan sepertinya sepakat dengan sebuah argumen bahwa Konten materi 
dalam PPKn harus mendukung pengembangan kompetensi kewarganegaraan yang terdiri dari pengetahuan, keterampilan, dan sikap. (Branson \& Quigley, 1998)

Pendidikan kewarganegaraan sendiri mengalami penyesuaian berkaitan dengan pergantian kurikulum pendidikan nasional. Hal yang menarik dalam perubahan ini khususnya pada PKn, perubahan tidak sebatas pada kontens materi, capaian pembelajaran dan muatan pembelajaran, tapi juga pada nomenklatur atau istilah yang digunakan. Setidaknya PKn pernah menggunakan istilah Civic, Pendidikan Moral Pancasila, Pendidikan Kewarganegaraan, dsb. Perubahan ini tentu banyak berdampak pada persepsi bahwa kurikulum dan pembelajaran PKn bersifat volatile dan unstable.

Persepsi tersebut bukan muncul dari masyarakat luas, bahkan ujung tombak, suksesor, sekaligus promotor subyek ini, yaitu guru memunculkan anggapan yang serupa. Ketidaktentuan itu membuat para guru kemudian mencari jalan singkat, yaitu bertindak partikular sesuai dengan latar belakang kualifikasi, minat dan ideologi. Sehingga berdampak pada penyajian yang beragam dan berujung pada kebingungan guru. Tentu sangat berisiko jika ujung tombaknya saja kebingungan.

Kebingungan mengenai di mana sebetulnya posisi, bagaimana komposisi dan seperti apa strategi transmisi PKn justru memerlukan pencerahan sekaligus kejelasan konseptual dan prosedural. Dalam konteks sekolah dasar, PKn sebagai pendidikan yang menggunakan pendekatan interdisipliner memiliki momentumnya. (Abdillah, 2016) Dengan sistem pembelajaran yang tematik integratif, justru memerlukan guru yang memiliki kompetensi multiliterasi, referensi multimodal, dan paradigma yang multiperspektif. Sehingga pengembangan PKn dapat dikembangkan sesuai dengan muatanmuatan yang terdapat dalam Pendidikan Kewarganegaraan, yang menyesuaikan dengan konten materi yang akan dibelajarkan. Jika pun agar optimal, apa yang dimaksud sebagai warga negara yang baik perlu lebih banyak didefinisikan oleh guru agar kesadaran dan pengetahuan seperti apa yang perlu dikembangkan lagi oleh guru karena persepsinya. (Li \& Tan, 2017) Sementara itu, Australia mengembangkan kurikulum untuk PKn bertolak dari konsep warga negara aktif. (Peterson \& Bentley, 2017). Walau perlu juga edukator PKn dan mahasiswa calon guru untuk memahami kontradiksi antara tensi dan potensi dalam memperkuat definisi apa itu warga negara aktif di lingkungan pendidikan. (Mayes, Mitra, \& Serriere, 2016)

Tentu untuk penyesuaian strategi didaktis-pedagogis tersebut, diperlukan guru yang memiliki persepsi, kompetensi, kualifikasi dan referensi yang cukup. Maka studi ini menelusuri mengenai hal yang sebelumnya belum membawa basis data dan argumen yang mencukupi untuk menjawab permasalahan seperti masih terbatasnya referensi mengenai seperti apa perspektif guru sekolah dasar terhadap materi dan strategi yang secara prospektif cocok untuk PPKn SD.

Mengingat guru SD pada dasarnya tidak secara khusus mempelajari PPKn seperti halnya guru PPKn di Sekolah Menengah Pertama (SMP) dan Sekolah Menengah Atas (SMA), asumsi dasarnya di sini tentu ada perbedaan perspektif. Lalu dari perspektif tersebut, tentu kita selanjutnya dapat menakar bagaimanakah guru SD mengembangkan pembelajaran PPKn dan apakah materi PPKn di SD mencukupi dan mampu menyesuaikan dengan tujuan pembelajaran PPKn di SD.

Di sekolah dasar, adalah tingkatan yang tepat untuk memulai pengembangan kebajikan 
kepedulian terhadap intelektual (Virtues of Intellectual carefulness) seperti singlemindedness, thoroughness, accuracy, dan perseverance. (Murphy, 2007). Maka, kebutuhan akan meningkatkan motivasi siswa, kualitas pembelajaran dan luaran pembelajaran yang diharapkan (Liem \& Chua, 2013) memiliki urgensinya. Hal tersebut selain didasari oleh pemikiran intuitif yang menyebutkan bahwa jika guru menguasai sesuatu, tentu jika mereka mengajari pada orang lain hal tersebut, pembelajaran dan hasilnya upaya tersebut akan optimal pula, misal seperti studi yang telah dilakukan pada pelajaran matematika (Hill, Rowan, \& Ball, 2005) sehingga pendidikan untuk mempersiapkan calon guru menjadi penting itu semakin relevan. (Ma, 1999)

Perlunya mendukung siswa dalam menghadapi permasalahan yang kompleks, pendidikan perlu mengintegrasikan pengembangan pengetahuan, keterampilan, nilai, dan perilaku ke dalam kurikulum, pengabdian masyarakat, dan pembelajaran akademik secara serentak agar terciptanya pendidikan yang inklusif. (Dias \& Soares, 2017) Hal tersebut juga berkaitan dengan prinsip bahwa pendidikan tidak terbatas pada pengetahuan teknis dan keterampilan semata. (UNESCO, 2015)

Area pengembangan pada PKn seperti disposisi, keterampilan dan sikap bisa berkontribusi dalam pengembangan percaya diri sekaligus motivasi siswa untuk melakukan perubahan di dunia nyata. (Flanagan, 2013)

Sejauh ini, data terbatas atau pun yang lebih komprehensif terkait hal di atas belum tersedia secara mencukupi. Maka studi ini memiliki urgensi untuk dilaksanakan sebagai dasar pengembangan pembelajaran di sekolah juga sebagai rekomendasi kebijakan di tingkat universitas.

\section{METODE PENELITIAN}

Penelitian ini dilaksanakan dengan pendekatan penelitian kualitatif. Dalam menganalisis, penelitian ini menggunakan pisau bedah analisis konten, dan untuk menganalisis persepsi dan prinsip implementasi oleh para guru dengan metode penelitian Grounded Theory. Penelitian ini dilaksanakan selama 3 bulan dan berlokasi di Kota dan Kabupaten Bandung, Jawa Barat. Subyek penelitian ini adalah 8 orang partisipan terdiri dari guru SD yang dipilih secara purposif. Pemilihan dan penggunaan desain ini terkait dengan tujuan penelitian yaitu untuk mengeksplorasi dan menganalisis bagaimana para guru sekolah dasar mengonstruksi pemahaman dan mengembangkan pembelajaran. Pengumpulan data penelitian ini dilakukan melalui observasi, dan wawancara dengan pertanyaan semiterstruktur dengan melibatkan 18 orang pengumpul data. Dalam metode penelitian Grounded Theory, analisis data dilakukan dengan melakukan kodifikasi terhadap data dengan tiga tahapan (Strauss \& Corbin, 1998; Glaser \& Strauss, 2006), yaitu:

\section{Open Coding/Open Sampling}

Tahap ini dilakukan untuk segmentasi informasi mengenai pembentukan kategori awal atas fenomena yang diteliti. Data yang digunakan adalah hasil wawancara, observasi, dan memo (catatan-catatan penelitian) (Cresswell, 2012).

\section{Axial Coding}

Pada bagian ini, peneliti memilih satu kategori sebagai proses sentral dan menghubungkannya dengan kategori yang lain. Menurut Cresswell (2012), kategori-kategori ini biasanya terdiri dari:

\subsection{Causal Conditions - Kategori}

kondisi yang mempengaruhi kategori inti (core category/phenomena)

\subsection{Context /condition- Kondisi} spesifik yang mempengaruhi strategi 
1.3 Core Category/Phenomena - Ide utama atas fenomena inti sebuah proses

$1.4 \quad$ Intervening conditions - Kondisi umum kontekstual yang mempengaruhi strategi

1.5 Strategies - Tindakan spesifik atau interaksi yang dihasilkan dari fenomena inti

1.6 Consequences - Hasil yang didapat setelah menjalankan strategi

Seluruh tahapan ini disebut sebagai coding paradigm, yaitu tahap yang menggambarkan hubungan timbal balik (interrelationship) causal conditions, strategies, contextual and intervening conditions, dan consequences. (Cresswell, 2012).

\section{Selective Coding}

Mengutip pendapat Cresswell (2012, hal 426), "In the selective coding the grounded theorist writes a theory from the interrelationship of the categories in the axial coding model". Pada level dasar, teori ini menyediakan penjelasan abstrak atas proses yang sedang diteliti.

\section{HASIL PENELITIAN DAN PEMBAHASAN}

Dari hasil penelusuran melalui wawancara, terlihat beragam sisi yang dilihat dari pembelajaran PKn oleh para Guru. Misalnya seperti yang disampaikan oleh Guru A, menurutnya bahwa setiap kurikulum itu tentu memiliki kelebihan dan kekurangannya. PPKn di dalam kurikulum nasional ini dianggap bagus karena membuat anak dapat berpikir tinggi atau kritis. Akan tetapi di sini seringkali muncul bentuk pertanyaan-pertanyaan yang tidak masuk ke dalam logika berpikir anak. Terkadang pertanyaan yang muncul di dalam buku siswa itu terlalu jauh dari kemampuan berpikir anak pada kelas tersebut sehingga guru harus lebih menelusuri kembali kepada anak agar sampai pemahamannya kepada mereka. Kurikulum nasional ini sendiri memiliki kelebihan dibandingkan KTSP yaitu beban anak yang tidak terlalu banyak. Hanya saja di dalam buku siswa itu sendiri pengkajian materinya tidak mendasar dan hanya sekilas. Kalau di dalam KTSP per-mata pelajaran, PPKn itu dipegang oleh ahlinya (guru menguasai betul mengenai materi PPKn itu). Akan tetapi menjadi beban kepada anak karena di KTSP itu cakupannya lebih luas.

Di sisi lain, guru B memandang bahwa pembelajaran PKN pada Kurikulum 2013 sebenarnya lebih menonjol dari bidang lain, karena dalam PKN sendiri materi lebih berhubungan dengan karakteristik Kompetensi Inti 1 dan Kompetensi Inti 2 yang berkaitan dengan aspek Spiritual dan aspek Sosial. Dalam pembelajaran PKN pada kurikulum 2013 siswa lebih aktif dan lebih antusias dalam pembelajaran karena dalam kurikulum 2013 lebih menekankan pada anak untuk lebih aktif, kreatif, dan dapat memecahkan suatu permasalahan serta diarahkan untuk bisa berpikir kritis.

Menyetujui hal tersebut, Guru C melihat bahwa dalam pelaksanaan pembelajaran materi PPKn lebih sederhana jika dibandingkan dengan pembelajaran PPKn di kurikulum KTSP atau 2006 yang syarat kepada materi yang luas karena pada kurikulum 2013 ini dalam satu tema hanya terdapat beberapa materi yang dibahas dan itu juga diintegrasikan dengan materi pelajaran lain. Selain itu, materi PPKn yang diajarkan pun harus disesuaikan dengan KI dan KD mata pelajaran PPKn tersebut agar capaian yang dihasilkan pun sesuai. Adapun tanggapan dari guru mengenai pembelajaran PPKn dalam kurikulum 2013 ini memudahkan bagi guru karena materi dan mata pelajaran yang harus diintegrasikan nya telah ada pada buku guru dan siswa sehingga memudahkan dalam pembuatan RPP. Akan tetapi jika ditinjau dari keluasan materinya memang lebih luas pada kurikulum KTSP karena materi lebih bersifat parsial dan terfokus. 
Bertemali dengan hal tersebut, Guru D melihat bahwa pembelajaran PPKn dalam Kurikulum 2013 ini dirasa lebih mudah dan efektif karena pada kegiatan mengajar, salah satu contohnya dalam pembuatan Rancangan Pelaksanaan Pembelajaran(RPP) lebih efisien karena hanya membuat satu Rancangan Pelaksanaan Pembelajaran(RPP) yang didalamnya sudah memuat beberapa mata pelajaran dan dibandingkan dengan pembelajaran PPKn pada Kurikulum Tingkat Satuan Pendidikan (KTSP) yang bersifat parsial dimana

Rancangan

Pelaksanaan Pembelajaran(RPP) dibuat secara terpisah pada masing-masing mata pelajaran sehingga membutuhkan waktu yang cukup banyak.

Pada bagian penelaahan data mengenai persepsi guru dan prospek guru terhadap pengembangan pembelajaran ini, data yang dianalisis merupakan hasil observasi, studi dokumentasi dan wawancara secara mendalam dengan para guru. Di bawah ini merupakan bagan hasil penelusuran dan kategorisasi perspektif guru terhadap urgensi pengembangan pembelajaran PPKn di SD. Hasil kalibrasi tersebut tersajikan dalam bagan di bawah ini.

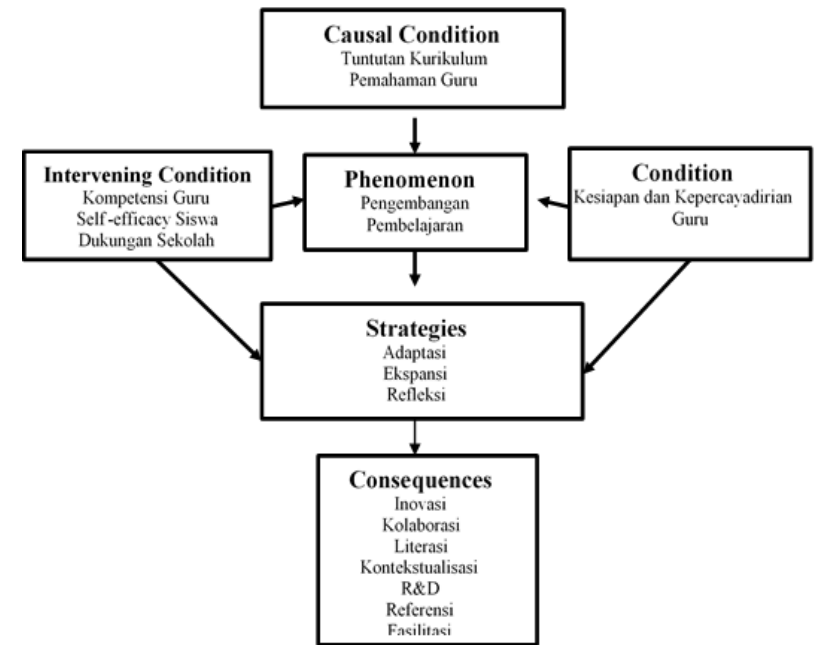

Figure 1. Hasil penelusuran dan kategorisasi perspektif guru terhadap urgensi pengembangan pembelajaran PPKn di SD

Jika kita mengacu pada Bagan ini, maka kita akan mendapatkan gambaran terkait persepsi guru mengenai prospek pengembangan pembelajaran PPKn di Sekolah Dasar. Tentu secara unik kesiapan dan kepercayaan dirian dari guru menjadi problematika disaat guru merasa bahwa kualifikasi akademiknya kurang mendukung pengetahuannya untuk melaksanakan pengembangan, yang kemudian berdampak pada bagaimana ia mengembangkan pembelajaran yang akhirnya justru tidak optimal. Akan tetapi hal tersebut bisa berubah, ketika hal-hal positif terkait kesiapan dan kepercayaan diri ada, hal tersebut banyak membantu bagaimana guru justru melakukan percobaan dan pengembangan pada pembelajaran.

Dengan mencoba mengadaptasi modelmodel yang telah dipelajari dan sedang ramai di pelatihan-pelatihan untuk guru, kemudian proses ini menjadi terbantu, baik dalam fase awal atau pun akhir. Tidak sekadar adaptasi, tapi ekspansi cakupan serta kajian pembelajaran diperluas, yang perlu diperhatikan justru adalah konteks, sehingga tidak tercerabut dari kebutuhan dan tuntutan pendidikan di Sekolah Dasar.

Dan refleksi, akan selalu menjadi hal yang tidak bisa ditinggalkan karena kadar urgensinya yang melekat. Refleksi yang membantu guru untuk berubah, untuk melakukan sesuatu dan untuk rendah hati mencari kekurangannya agar segera diperbaiki. Jika hal di atas muncul, maka inovasi yang diharapkan muncul dari proses kolaborasi akan muncul dalam pemahaman guru, sehingga tingkat literasi dari guru yang tinggi juga dapat mensponsori tingkat literasi dari muridmuridnya.

Referensi yang dijadikan bahan untuk pelaksanaan Penelitian Tindakan Kelas, agar guru mengetahui seberapa ampuh strategi pembelajaran, media pembelajaran, dan hal lainnya dalam proses pembelajaran untuk mengetahui kekurangan serta kelebihan dari upaya yang sudah dilakukannya, maka tentu hal 
ini menjadi bahan refleksi, yang selanjutnya bisa diajukan sebagai bahan fasilitasi dalam bentuk pelatihan atau pun seminar bagi guru sekolah dasar. Tentu di sini kebutuhan akan guru yang memiliki kemampuan reflektif muncul, misalnya dengan media jurnal reflektif yang secara periodik menjadi stimulus guru untuk terus memperbaiki kualitas diri dan pembelajarannya. (Abdillah, 2017) Agar pengembangannya pun tetap kontekstual dan bermakna bagi pelaku pembelajaran.

Dari hasil wawancara dengan guru kelas mengenai materi Mentaati Nilai-Nilai Pancasila dan Perbuatannya di SD, tidak semata-mata merupakan pemberian penjelasan mengenai materi secara eksplisit karena tingkat kemapuan berpikir mereka masih sangat abstrak sehingga perlu data-data konkrit atau pemodelan dalam pembelajaran. Pembahasan secara meluas tersebut seperti yang dikatakan oleh (Gainous \& Martens, 2012) yang membuat efikasi siswa dalam pembelajaran PKn perlahan mengalami peningkatan. Secara komprehensif, materi PKn memang terdiri dari beragam disiplin dan cara pandang, maka diperlukan juga guru yanhg multilaterat melalui penguasaan multiliterasi. Oleh karenanya dalam penerapan pembelajarannya pun harus diselaraskan dengan pemahaman yang mereka miliki mengenai nilanilai pancasila yang ada di sekolah.

Cara guru dalam menerapkan pembelajaran dengan kurikulum 2013 biasanya menggunakan pendekatan kontekstual, diamana biasanya guru akan melalukan apresepsi di setiap pembelajarannya dengan bertanya mengnai pengetahuan awal siswa terhadap materi yang akan di pelajari oleh mereka. Salah satu contohnya adalah ketika guru tersebut memberi intruksi kepada siswa agar membawa makanan daerahnya masing-masing ke sekoalah kemudian saling bertukar makanan anatar siswa yang berbeda daerah, hal tersebut berhasil membuat siswa menyadari adanya perbedaan di antara siswa dengan siswa yang lainnya namun mereka mendapat esensi bahwa ternyata perbedaan makanan daerah tersebut adalah suatu keberagaman yang indah karena meski berbedabeda namun semua makanan daerah tersebut di rasa enak.

Para guru merasa bahwa membelajarkan PKN dalam kurikulum 2013 tidak terasa sulit, karena nilai-nilai karakter ada di setiap mata pelajaran sehingga ketika materi PKN di masukan dalam pengintegrasian dari suatu pembelajaran tidak akan sulit karena sudah adanya pembiasaan pendidikan karakter di materi-materi lain, sehingga dampak dari adanya pembiasaan tersebut guru tidak sulit lagi dalam menerapkan nilai nilai karakter, karena hal tersebut sudah ada penyadaran dari peserta didik. Akan tetapi, perlu dicatat bahwa nilainilai yang dikembangkan perlu selaras dengan visi PKn, dan kalau pun tidak sesuai bisa diacuhkan saja. (Cavieres-Fernández, 2017) Sehingga, kebutuhan proses pembelajaran untuk meningkatkan motivasi siswa, kualitas pembelajaran dan luaran pembelajaran yang diharapkan (Liem \& Chua, 2013) bisa terwujud. Pengembangan motivasi belajar siswa yang cukup multidimensi ini perlu menjadi perhatian lebih dari guru SD saat pembelajaran PKn.

\section{SIMPULAN DAN SARAN}

\section{Simpulan}

Materi ajar PKn dengan ruang lingkup yang sudah ditentukan oleh UU sudah dinilai sesuai dengan konteks sekolah dasar, tujuan pendidikan nasional dan kondisi siswa sekolah dasar yang berorientasi pada masa lalu, masa kini dan masa depan, sehingga dapat mewujudkan Virtues of Intellectual carefulness dari tiap siswa.

Persepsi guru pada konten materi PPKn di Kurikulum Nasional revisi 2016 berkaitan dengan mengembangkan Pembelajaran PPKn di 
Sekolah Dasar beragam, akan tetapi semuanya memiliki persamaan persepsi, bahwa mata pelajaran ini dianggap sebagai media paling relevan untuk meningkatkan kesadaran siswa terhadap nilai, moral, kecakapan hidup bermasyarakat nantinya.

\section{Saran}

Peneliti selanjutnya diharapkan untuk menelusuri data yang lebih komprehensif sehingga dapat digeneralisasi lebih jauh. Dan untuk Prodi PGSD diharapkan agar konten materi perkuliahan ke-PKn-an di pendidikan guru SD juga harus berorientasi pada pemenuhan akan pendalaman pada kesadaran siswa terhadap nilai, moral, kecakapan hidup bermasyarakat.

\section{DAFTAR PUSTAKA}

Abdillah, F. (2016, December). Interdisipliner: Refleksi Epistemologis Pendidikan Kewarganegaraan Di Sekolah Dasar. In International Seminar on Philosophy of Education: Primary Foundation in Strengthening Pedagogy Development in Indonesia Future Generation (pp. 138141).

Abdillah, F. (2017). Revitalisasi Kemampuan Refleksi Mahasiswa Calon Guru Melalui Penulisan Jurnal Perkuliahan PPKn. EDUHUMANIORA: Jurnal Pendidikan Dasar, 9(1), 8-15.

Branson, M. S., \& Quigley, C. N. (1998). The Role of Civic Education. Calabasas: Center for Civic Education.

Creswell, J. W. (2012). Educational research : planning, conducting, and evaluating quantitative and qualitative research (4th ed.). Boston, MA: Pearson Education.

Cavieres-Fernández, E. (2017). Teacher counter stories to a citizenship education mega policy narrative. Preparing for citizenship in Chile. Journal of Curriculum Studies, 49(4), 414-436.

Dias, D., \& Soares, D. (2017). Civic learning outcomes: a step towards an inclusive higher education. International Journal of Inclusive Education, 1-15.

Flanagan, C. (2013). Teenage citizens: The political theories of the young. Boston, MA: Harvard University Press.

Gainous, J., \& Martens, A. (2012). The Effectiveness of Civic Education: Are "Good" Teachers Actually Good for "All" Students? American Politics Research, 40(2), 232-266.

Glaser, B. G., \& Strauss, A. L. (2006). The Discovery of Grounded Theory. London: AldineTransaction.

Hill, H. C., Rowan, B., \& Ball, D. L. (2005). Effects of teachers' mathematical knowledge for teaching on student achievement. American Educational Research Journal, , 42(2), 371-406.

Li, H., \& Tan, C. (2017). Chinese teachers' perceptions of the 'good citizen': A personally-responsible citizen. Journal of Moral Education, 46(1), 34-45.

Liem, G. A., \& Chua, B. L. (2013). An expectancy-value perspective of civic education motivation, learning and desirable outcomes. Educational Psychology, 33(3), 283-313.

Ma, L. (1999). Knowing and teaching elementary mathematics: Teachers' understandings of fundamental mathematics in China and the United States. Mahwah, NJ: Lawrence Erlbaum.

Mayes, E., Mitra, D., \& Serriere, S. (2016). Figured Worlds of Citizenship: Examining Differences Made in "Making a Difference" in an Elementary School Classroom. American Educational Research Journal, 53(3), 605-638.

Murphy, J. B. (2007). Against Civic Education in Public Schools. Internationall Journal of Public Administration, 30, 651-670.

Parker, W. C. (2011). Social studies in elementary education. Newmarket, ON: Pearson Education.

Peterson, A., \& Bentley, B. (2017). A case for cautious optimism? Active citizenship and the Australian civics and citizenship curriculum. Asia Pacific Journal of Education, 37(1), 42-54. 
Strauss, A., \& Corbin, J. (1998). Basics of Qualitative Research: Techniques and Procedures for Developing Grounded Theory. California: Sage Publications, Inc.

UNESCO. (2015). Rethinking Education: Towards a Global Common Good? Paris: UNESCO Publishing. 